\title{
Article \\ The Use of Electronic Nose in the Quality Evaluation and Adulteration Identification of Beijing-You Chicken
}

\author{
Jingru Chen ${ }^{1}$, Wenjie Yan ${ }^{2}$, Yu Fu ${ }^{3}$, Liang Wang ${ }^{4}$, Xueze Lv ${ }^{4}$, Ruitong Dai ${ }^{1}$, Xingmin Li ${ }^{1, *}$ and Fei Jia ${ }^{5, *}$ \\ 1 College of Food Science and Nutritional Engineering, China Agricultural University, No. 17 Qinghua East Road, \\ Haidian District, Beijing 100083, China; 18800120616@163.com (J.C.); dairuitong@vip.sina.com (R.D.) \\ 2 College of Biochemical Engineering, Beijing Union University, Beijing 100023, China; \\ meyanwenjie@buu.edu.cn \\ 3 Department of Food Science, Southwest University, Chongqing 400715, China; fuy987@swu.edu.cn \\ 4 Animal Husbandry Station of Beijing, No. 17 Beiyuan Road, Chaoyang District, Beijing 100101, China; \\ carspstp@126.com (L.W.); lvxueze0310@163.com (X.L.) \\ 5 Department of Biological and Agricultural Engineering, University of Arkansas, Fayetteville, AR 72701, USA \\ * Correspondence: lixingmin@cau.edu.cn (X.L.); feijia@uark.edu (F.J.)
}

check for

updates

Citation: Chen, J.; Yan, W.; Fu, Y.;

Wang, L.; Lv, X.; Dai, R.; Li, X.; Jia, F. The Use of Electronic Nose in the Quality Evaluation and Adulteration Identification of Beijing-You Chicken. Foods 2022, 11, 782. https://doi.org/ 10.3390 /foods 11060782

Academic Editors: María Del

Mar Campo Arribas and

Saskia Van Ruth

Received: 17 December 2021

Accepted: 14 February 2022

Published: 8 March 2022

Publisher's Note: MDPI stays neutral with regard to jurisdictional claims in published maps and institutional affiliations.

Copyright: (C) 2022 by the authors. Licensee MDPI, Basel, Switzerland. This article is an open access article distributed under the terms and conditions of the Creative Commons Attribution (CC BY) license (https:// creativecommons.org/licenses/by/ $4.0 /)$.

\begin{abstract}
The objective of this study was to reveal the secrets of the unique meat characteristics of Beijing-you chicken (BJY) and to compare the difference of quality and flavor with Luhua chicken (LH) and Arbor Acres broiler (AA) at their typical market ages. The results showed the meat of BJY was richer in essential amino acids, arachidonic acid contents, inosine monophosphate (IMP), and guanosine monophosphate (GMP). The total fatty acid and unsaturated fatty acid contents of BJY chicken and LH chicken were lower than that of AA broilers, whereas the ratios of unsaturated fatty acids/saturated fatty acids (2.31) and polyunsaturated fatty acids/monounsaturated fatty acids (1.52) of BJY chicken were the highest. The electronic nose and SPME-GC/MS analysis confirmed the significant differences among these three chickens, and the variety and relative content of aldehydes might contribute to a richer flavor of BJY chicken. The meat characteristics of BJY were fully investigated and showed that BJY chicken might be favored among these three chicken breeds with the best flavor properties and the highest nutritional value. This study also provides an alternative way to identify BJY chicken from other chickens.
\end{abstract}

Keywords: Beijing-you chicken; meat quality; flavor; GC-MS; electronic nose

\section{Introduction}

Beijing-you (BJY) chicken, as one of 27 rare breeds in China, is increasingly favored by Chinese customers for its superior meat and egg qualities [1]. In 2020, BJY chicken was awarded the "Agro-product Geographical Indications" by the Ministry of Agriculture of the P.R.C., due to its distinctive appearance, strong viability, and stable genetic performance [2]. As a result, the price of BJY chicken of approximately RMB 70/500 $\mathrm{g}$ is much higher than other commercially available chickens. However, very few researchers focus on investigating the quality and flavor characteristics of BJY chicken and adulteration identification technology to differentiate BJY chicken from other low-value chickens, which could help BJY chicken to remain competitive in the market.

Consumer acceptance of chicken meat relies on its quality, such as visual appearance, smell, tenderness, and juiciness [3]. Nowadays, nutrition and sensory quality are noted as key factors in the consumer perception of chicken meat [4,5]. Among them, the flavor, including taste and odor, is one of the most important characteristics [6]. Taste is the sensation that the tongue receives when it contacts with soluble substances, such as free amino acids and nucleotides, while the odor is sensed through the olfactory organs [7]. Gas chromatography-mass spectroscopy (GC/MS) is the most commonly technique to analyze odor profiles of meat products, which could provide an accurate approach for the 
qualitative and quantitative analysis of volatile compounds [8]. Solid-phase microextraction (SPME) has the advantages of simplicity of operation, speed, a solvent-free nature, analyte separation, and preconcentration [6]. The electronic nose is a device that consists of a multi-sensor array and multidimensional signal processing of the array signal by pattern recognition algorithms [9] and can measure the presence of volatile compounds related to the meat aroma. In this technique, the analytic process does not concentrate on the identification and quantification of the volatile compounds but rather on the quantitative description of the complete aroma profile, including the relationships between its components [10]. Compared with traditional sensory evaluation and physicochemical techniques, which are expensive and time consuming, the electronic nose provides an efficient, rapid, non-destructive, and real-time testing, and this technique is widely used in freshness evaluation [11], shelf-life investigation [12], meat product authenticity [13,14], and flavor distinction $[15,16]$.

Compared with the commercial fast-growing broiler breeds, such as Arbor Acres broiler (AA), the slow-growing native chicken is more preferred in Asian areas because of its high nutrition value, unique organoleptic characteristics, and special flavors [17-19]. An increasing number of people prefer to buy native chickens, even when the price is approximately two to four times higher than the commercial broiler. Luhua (LH) chicken is a Chinese local chicken breed that is widely raised in rural areas in China. Generally, local chickens in China, including BJY chicken and LH chicken, will be used for meat production at 30-40 weeks of age [1]. The imported commercial broiler, however, usually takes approximately 42 days in growth, which makes it the main chicken meat in Chinese supermarkets, especially in the fast-food industry.

In this study, the quality and flavor of BJY chicken were fully investigated, and commercial broilers (AA) and common and widely raised Chinese chicken breed chicken (LH) were selected as two typical chickens to investigate the differences in meat quality and flavor. Specifically, both nonvolatile compounds (fatty acids, amino acids, and IMP and their relative contents) and volatile organic compounds (VOCs) of the three chickens, which contribute to the sensory properties, were measured and compared in detail. Meanwhile, the electronic nose was also used to characterize and classify the differences of volatile compounds of these three chicken breeds. By comparing the difference in flavor and quality of these three types of chicken, we attempt to reveal the meat characteristics of BJY chicken and provide a possible identification method.

\section{Materials and Methods}

\subsection{Sample Collection}

BJY chicken (aged 240 days with a live weight of 2.0-2.5 kg) and LH chicken (aged 240 days with a live weight of 2.0-2.5 kg) were purchased from Beijing Xiqing Minfeng Agricultural Development Co., Ltd. (Beijing, China). Experimental animals of these two breeds ( 5 birds per breed, respectively) were slaughtered by conventional neck cut, bled for $2 \mathrm{~min}$, defatted, and eviscerated. The breast (pectoralis major) muscles were dissected carefully. All operations were carried out in accordance with the Guidelines for experimental Animals established by the Ministry of Science and Technology (Beijing, China). Five AA broilers (aged 42 days and with live weight 1.5-2.0 kg) were purchased from Beijing Huadu Poultry Breeding Co., Ltd. (Beijing, China).

\subsection{Determination of Intramuscular Fat (IMF) and Crude Protein (CP)}

IMF content was measured as described by Ju et al. [20], with slight changes. A minced meat sample $(5 \mathrm{~g})$ of each chicken was mixed with $50 \mathrm{~mL}$ of petroleum ether to ultrasonically extract the IMF for $45 \mathrm{~min}$. Extracted IMF was filtered, dried with anhydrous $\mathrm{Na}_{2} \mathrm{SO}_{4}$, and concentrated by rotary evaporator in a $70^{\circ} \mathrm{C}$ water bath. The above steps were repeated three times to obtain IMF. The results were expressed as the weight percentage of wet muscle tissue. 
The nitrogen $(\mathrm{N})$ content was assayed using the Kjeldahl method, which was used to calculate $\mathrm{CP}$ by multiplying $\mathrm{N} \times 6.25$. The results were expressed as the weight percentage of wet muscle tissue.

\subsection{Determination of Nucleotide Compound Contents}

Nucleotide content was estimated as described by Jung et al. [21], with slight changes. A minced meat sample (5 g) of each chicken was mixed with $20 \mathrm{~mL}$ of $5 \%$ (volume/volume) perchloric acid to extract nucleic acids. Extracted nucleic acids were centrifuged at $9200 \times g$ for $10 \mathrm{~min}$. The supernatant was then adjusted to $\mathrm{pH} 6.4$ with $1 \mathrm{~mol} / \mathrm{L} \mathrm{KOH}$. The supernatant was placed in a volumetric flask and adjusted to a volume of $25 \mathrm{~mL}$ with distilled water, filtered through a $0.22 \mu \mathrm{m}$ membrane filter, and analyzed for adenosine triphosphate (ATP), and its related compounds were measured by HPLC (Shimadzu, Kyotos, Japan) equipped with an SPD-10A (V) detector, VP-CDS C18 column (4.6 mm id $\times 250 \mathrm{~mm}, 5 \mu \mathrm{m})$. The sample $(10 \mu \mathrm{L})$ was injected at a flow rate of $0.7 \mathrm{~mL} / \mathrm{min}$, and the peak was detected at $254 \mathrm{~nm}$. The amounts of ATP, adenosine diphosphate (ADP), adenosine monophosphate (AMP), IMP, inosine (HxR), hypoxanthine (Hx), and GMP were determined and calculated based on the standard ATP, ADP, AMP, IMP, HxR, Hx, and GMP. All standards reagents were purchased from Sigma (Merck, Darmstadt, Germany). The results were expressed as milligram of nucleotides contents per $100 \mathrm{~g}$ of wet muscle tissue.

\subsection{Determination of Amino Acid Contents}

Amino acid content was estimated based on the previous methods reported by Li et al. [22]. Breast muscle samples $(2 \mathrm{~g})$ were freeze-dried and ground for extraction, then amino acids were determined in triplicate by an Amino Acid Analyzer (Sykam, Munich, Germany). The results were expressed as milligrams of amino acids per $100 \mathrm{~g}$ of wet muscle tissue.

\subsection{Determination of Fatty Acids}

Fatty acid content was determined by gas chromatography, as reported by Gecgel [23]. Breast muscle samples were freeze dried and ground and then analyzed using an HP6890 gas chromatography system (Hewlett-Packard, Palo Alto, CA, USA). The results were expressed as milligrams of fatty acids per $100 \mathrm{~g}$ of wet muscle tissue.

\subsection{Determination of VOCs}

The VOCs were determined by an automated injector using the method introduced by Li et al. [24], with some modifications. Meat samples weighing $1 \mathrm{~g}$ were placed into $20 \mathrm{~mL}$ headspace vials prior to being pre-heated at $60^{\circ} \mathrm{C}$ for $20 \mathrm{~min}$ for system equilibration. PDMS/DVB fiber $(65 \mathrm{~mm}$ ) was inserted and exposed to the headspace of the vial. After $30 \mathrm{~min}$, the fiber was withdrawn and inserted into the injection port of a GC (Shimadzu, Kyoto, Japan) injector at $200{ }^{\circ} \mathrm{C}$ for 2 min for desorption.

In a GC-MS system equipped with an MS detector (Shimadzu, Kyoto, Japan), VOCs were separated by a capillary DBWAX column $(30 \mathrm{~m} \times 0.25 \mathrm{~mm} \times 0.25 \mathrm{~mm})$. The temperature of the GC oven was first kept at $40^{\circ} \mathrm{C}$ for $3 \mathrm{~min}$, increased $5{ }^{\circ} \mathrm{C} / \mathrm{min}$ to $120^{\circ} \mathrm{C}$, and then increased $10^{\circ} \mathrm{C} / \mathrm{min}$ to $200{ }^{\circ} \mathrm{C}$ and held for $13 \mathrm{~min}$. The injections were performed in splitless mode, and the carrier gas was helium with a flow rate of $1 \mathrm{~mL} / \mathrm{min}$. The collection of MS data was acquired at a full scan range from 35 to $500 \mathrm{~m} / \mathrm{z}$. The transfer lines and MS source remained at $250{ }^{\circ} \mathrm{C}$ and $200{ }^{\circ} \mathrm{C}$, respectively. The VOCs were identified by matching mass spectra or retention time with those in the National Institute of Standards and Technology (NIST) 11 spectral database and were quantified by the area normalization method.

\subsection{Electronic Nose Evaluation}

The volatile compounds of chicken breast meat were analyzed using an E-Nose 10001 system (developed by the College of Information and Electrical Engineering, China Agricultural University). The E-Nose 10001 electronic nose system mainly consists of the following parts: data acquisition part, data conditioning part, interface circuit part, and 
computer host. The hardware part includes a gas sensor array, a signal conditioning circuit board, an A/D conversion interface, and a computer, as shown in Figure 1. Previous studies have proven that, after the sensor array optimization and feature optimization, E-Nose 10001 can distinguished pork from different manufacturers, and also the parts and storage conditions. Compared with the PEN3 electronic nose of Airsense, the results of E-Nose 10001 are more accurate.

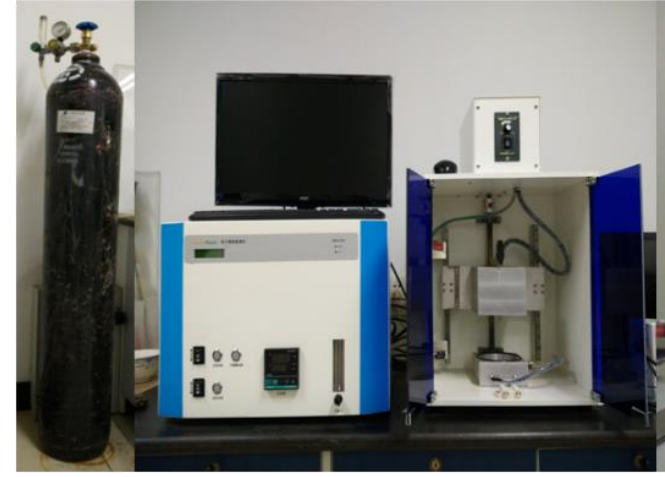

(a)

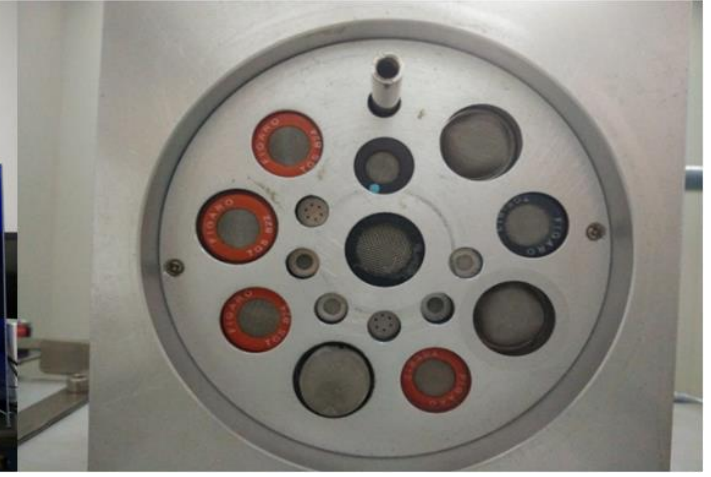

(b)

Figure 1. Electronic nose device (a) and gas sensor distribution (b).

The electronic nose was equipped with 16 different metal oxide sensors: TGS824, TGS822, TGS825, TGS880, TGS812, TGS831, TGS813, TGS830, TGS822TF, TGS2600, TGS2620, TGS2611, TGS2602, TGS2620, TGS2610, TGS2201. Before the measurements were taken, the headspace gases were injected at a flux speed of $3 \mathrm{~L} / \mathrm{min}$ for $60 \mathrm{~s}$. Then, $5 \mathrm{~g}$ of minced chicken breast samples ( 3 birds per breed, respectively) were placed in a vial at a temperature of $40^{\circ} \mathrm{C}$. The gases in the headspace of the sample were pumped into a gas sensor chamber at the same speed. The electronic nose measurement interval was $0.05 \mathrm{~s}$. Electronic nose real-time responses to chicken breast samples were recorded with 5 replicates.

\subsection{Reagent Section}

All reagents and solvents used are listed in Table 1.

Table 1. List of reagents and solvents used.

\begin{tabular}{ccc}
\hline Reagents & Types & Manufacturer \\
\hline ATP & Chromatographically pure & Sigma \\
ADP & Chromatographically pure & Sigma \\
AMP & Chromatographically pure & Sigma \\
IMP & Chromatographically pure & Sigma \\
GMP & Chromatographically pure & Sigma \\
HxR & Chromatographically pure & Sigma \\
Hx & Chromatographically pure & Sigma \\
Methanol & Chromatographically pure & Fisher Scientific \\
N-hexane & Chromatographically pure & Fisher Scientific \\
N-heptane & Chromatographically pure & Fisher Scientific \\
Ethanol & Analytically pure & Solarbio \\
Sulfosalicylic acid & Analytically pure & Solarbio \\
Potassium hydroxide & Analytically pure & Solarbio \\
Phthalaldehyde & Analytically pure & Solarbio \\
Perchloric acid & Analytically pure & Solarbio \\
Potassium dihydrogen phosphate & Analytically pure & Solarbio \\
Dipotassium phosphate & Analytically pure & Solarbio \\
Petroleum ether & Analytically pure & Solarbio \\
Anhydrous sodium sulfate & Analytically pure & Solarbio \\
\hline
\end{tabular}




\subsection{Statistical Analysis}

Mean and standard deviations were calculated and subjected to analysis of variance. Duncan's test was used to test for differences between means, and the significance was defined at $p<0.05$ using SPSS 18.0 software (Chicago, IL, USA). The discriminant results of the electronic nose sensors for different chicken breast meat were based on canonical discriminant analysis (CDA).

\section{Results and Discussion}

\subsection{Contents of Muscle IMF and CP}

The IMF and CP contents of different breeds of chicken breast are presented in Figure 2. The CP contents of BJY and AA broilers were slightly higher than that of LH chicken, and there were no significant differences between BJY and AA broilers on the CP contents. Comparison of breeds revealed that breast IMF content was higher $(p<0.05)$ in BJY chicken $(0.41 \%)$, whereas IMF content was intermediate in LH chicken $(0.28 \%)$ and lowest in the AA broilers $(0.23 \%)$. IMF content has a close relationship with good flavor, juiciness, and improved tenderness of meat [25]. These similar results were also found in previous studies, where native chicken breeds had higher IMF contents than imported commercial broilers [26,27]. Both genes and environment could influence the IMF content of meat [28]. Ranran et al. [29] revealed the embryonic development-related proteome and metabolome signatures in the breast muscle and intramuscular fat of fast-growing (BJY) and slowgrowing chickens.

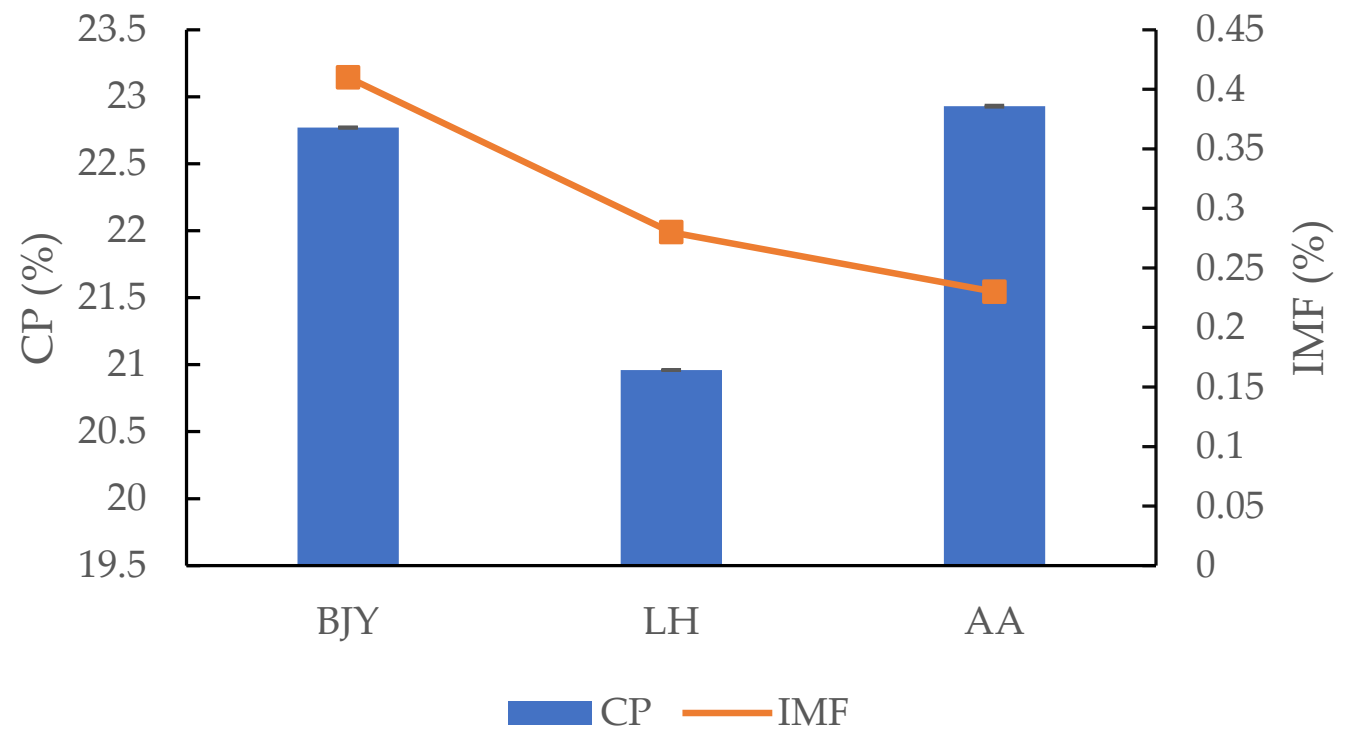

Figure 2. IMF and CP contents of different breeds of chicken breast.

\subsection{Contents of Nucleotide Compound}

From Table 2, the IMP contents of the breast meat from BJY and LH, which are $459.77 \mathrm{mg} / 100 \mathrm{~g}$ and $413.49 \mathrm{mg} / 100 \mathrm{~g}$, respectively, were significantly higher than AA broilers (247.25 mg/100 g). Some other studies have shown similar results; for example, Jung et al. [20] and Tang et al. [30] found that slow-growing chicken breeds in Korea and China had higher contents of IMP than fast-growing commercial broilers. The differences in IMP content among different breeds may be explained by the effects of genotype, age, or their interaction. In addition, there was genetic effect on IMP content in chicken meat among indigenous breeds [31]. Li et al. [22] found that the content of IMP from Wenchang chicken, another indigenous chicken from China, was highly related to their genotype. It has been widely accepted that IMP is the most important nucleotide-based flavor precursor and can produce a synergistic effect conjugated with monosodium glutamate [32]. 
Table 2. Nucleotide contents of different types of chicken breast (mg/100 g).

\begin{tabular}{cccc}
\hline Nucleotides & BJY & AA & LH \\
\hline GMP & $5.87 \pm 0.501^{\mathrm{a}}$ & $4.19 \pm 0.01^{\mathrm{b}}$ & $6.15 \pm 0.37^{\mathrm{a}}$ \\
IMP & $459.77 \pm 24.98^{\mathrm{a}}$ & $247.25 \pm 20.22^{\mathrm{b}}$ & $413.49 \pm 25.42^{\mathrm{a}}$ \\
Hx & $8.63 \pm 0.35^{\mathrm{a}}$ & $63.46 \pm 4.47^{\mathrm{c}}$ & $13.81 \pm 0.50^{\mathrm{b}}$ \\
HxR & $62.27 \pm 3.15^{\mathrm{a}}$ & $147.26 \pm 9.74^{\mathrm{b}}$ & $60.73 \pm 4.04^{\mathrm{a}}$ \\
\hline
\end{tabular}

$\overline{a, b, c}$ Means within a row with different superscripts differ significantly $(p<0.05)$.

GMP is another important nucleotides that provides pleasant flavor for meat and can also be used as a flavor enhancer [33]. The content of GMP in BJY (5.87 mg/100 g) and LH $(6.15 \mathrm{mg} / 100 \mathrm{~g})$ was significantly higher than that in AA $(4.19 \mathrm{mg} / 100 \mathrm{~g})$. The differences of GMP content may be explained by the effects of genotype, feed, age and feeding condition [34-38]. Over time after slaughter, IMP can degrade to HxR and Hx. It was reported that the accumulation of HxR and Hx led to a decrease in freshness [39]. Therefore, the relatively high IMP and GMP contents and lower content of Hx and HxR in the BJY breast meat may produce a better flavor compared with LH chicken and AA broilers.

\subsection{Contents of Amino Acids}

Free amino acids are of great importance in eating quality due to their specific tastes and important flavor and flavor precursor substance in chicken meat [40]. The amino acid profiles of breast meat from BJY, LH, and AA broilers are depicted in Table 3.

Table 3. Free amino acid contents of different types of chicken breast (mg/100 g).

\begin{tabular}{cccc}
\hline Amino Acid (mg/100 g) & BJY & LH & AA \\
\hline Asp (Aspartic acid) & $7.04 \pm 0.28^{\mathrm{b}}$ & $1.13 \pm 0.09^{\mathrm{a}}$ & $18.81 \pm 0.19^{\mathrm{c}}$ \\
Thr (Threonine) & $7.71 \pm 0.22^{\mathrm{b}}$ & $6.45 \pm 0.18^{\mathrm{a}}$ & $10.34 \pm 0.26^{\mathrm{c}}$ \\
Ser (Serine) & $4.56 \pm 0.04^{\mathrm{a}}$ & $6.16 \pm 0.17^{\mathrm{b}}$ & $7.84 \pm 0.40^{\mathrm{c}}$ \\
Glu (Glutamic acid) & $82.02 \pm 4.31^{\mathrm{a}}$ & $64.66 \pm 3.37^{\mathrm{b}}$ & $57.95 \pm 0.57^{\mathrm{b}}$ \\
Gly (Glycine) & $10.97 \pm 0.49^{\mathrm{a}}$ & $8.93 \pm 0.00^{\mathrm{b}}$ & $11.38 \pm 0.21^{\mathrm{a}}$ \\
Ala (Alanine) & $15.82 \pm 0.71^{\mathrm{a}}$ & $14.56 \pm 0.47^{\mathrm{a}}$ & $21.95 \pm 0.50^{\mathrm{b}}$ \\
Cys (Cystine) & $0.76 \pm 0.04^{\mathrm{a}} \mathrm{b}$ & $0.92 \pm 0.06^{\mathrm{b}}$ & $0.71 \pm 0.06^{\mathrm{a}}$ \\
Val (Valine) & $19.12 \pm 0.81^{\mathrm{a}}$ & $18.98 \pm 0.95^{\mathrm{a}}$ & $14.98 \pm 0.93^{\mathrm{b}}$ \\
Met (Methionine) & $9.05 \pm 0.37^{\mathrm{b}}$ & $6.14 \pm 0.26^{\mathrm{a}}$ & $11.88 \pm 0.14^{\mathrm{c}}$ \\
Ile (Isoleucine) & $21.10 \pm 0.62^{\mathrm{a}}$ & $18.92 \pm 0.55^{\mathrm{b}}$ & $16.19 \pm 0.16^{\mathrm{c}}$ \\
Leu (Leucine) & $30.10 \pm 0.60^{\mathrm{a}}$ & $26.44 \pm 0.18^{\mathrm{b}}$ & $25.74 \pm 0.55^{\mathrm{b}}$ \\
Tyr (Tyrosine) & $19.00 \pm 0.90^{\mathrm{a}, \mathrm{b}}$ & $18.33 \pm 0.01^{\mathrm{a}}$ & $20.21 \pm 0.23^{\mathrm{b}}$ \\
Phe (Phenylalanine) & $19.60 \pm 0.05^{\mathrm{a}}$ & $18.22 \pm 0.48^{\mathrm{b}}$ & $14.43 \pm 0.14^{\mathrm{c}}$ \\
His (Histidine) & $11.14 \pm 0.25^{\mathrm{a}}$ & $15.17 \pm 0.27^{\mathrm{b}}$ & $18.30 \pm 0.14^{\mathrm{c}}$ \\
Lys (Lysine) & $21.18 \pm 0.26^{\mathrm{a}}$ & $19.19 \pm 0.89^{\mathrm{b}}$ & $20.10 \pm 0.31^{\mathrm{ab}}$ \\
Arg (Arginine) & $8.96 \pm 0.57^{\mathrm{a}}$ & $10.00 \pm 0.46^{\mathrm{a}}$ & $19.79 \pm 0.12^{\mathrm{b}}$ \\
Pro (Proline) & $7.94 \pm 1.0^{\mathrm{a}}$ & $9.16 \pm 0.29^{\mathrm{a}}$ & $24.64 \pm 0.05^{\mathrm{b}}$ \\
EAA & $127.84 \pm 0.04^{\mathrm{a}}$ & $114.34 \pm 2.76^{\mathrm{b}}$ & $113.64 \pm 0.58^{\mathrm{b}}$ \\
Total & $296.02 \pm 3.70^{\mathrm{b}}$ & $263.33 \pm 0.25^{\mathrm{a}}$ & $315.20 \pm 1.77^{\mathrm{c}}$
\end{tabular}

$\mathrm{a}, \mathrm{b}, \mathrm{c}$ Means within a row with different superscripts differ significantly $(p<0.05)$. EAA $=$ essential amino acids (including threonine, valine, methionine, isoleucine, leucine, phenylalanine, and lysine).

It is clear that the predominant amino acids in the essential fraction were leucine and lysine in all chicken breeds. In the nonessential fraction, glutamic acid was the richest amino acid. Similar results were also reported in previous studies. Chen et al. [5] found that glutamic acid in the nonessential fraction and lysine and leucine in the essential fraction were also major amino acids in 817 crossed chickens (a commercial Chinese crossed chicken), AA broilers, and Hyline Brown (commercial spent hens). The same results were also found in some other meat such as eland, cattle [41], and goose [42]. 
In this study, different chickens were significantly different $(p<0.05)$ in their amino acid contents, with the exception of glutamic acid, glycine, alanine, valine, leucine, arginine, and proline in the breast. Regarding total essential amino acids, significant differences were found among all three groups. AA broilers contained relatively higher total essential amino acids (315.20 mg/100 g), followed by BJY and LH (296.02 mg/100 g and 263.33 mg/100 g, respectively). However, the essential amino acid contents of BJY chicken showed significantly higher values than LH and AA broilers in breast meat. Glutamic acid is an important flavor compounds of meat, which is an important contributor to the fresh taste of meat [43]. BJY chicken had the highest content of glutamic acid $(82.02 \mathrm{mg} / 100 \mathrm{~g})$ among these three chicken breeds. The content of glutamic acid in LH chicken was slightly higher than that in AA broilers, but there was no significant difference. Wattanachant et al. [44] also confirmed that the breast meat of Thai native chickens had higher glutamic acid compared with broiler chickens. Therefore, the results indicate that the chicken breed considerably affects the amino acid composition considerably. The high content of essential amino acids in the breast muscles of BJY chicken might suggest that the BJY chicken has more nutritional value to humans than LH and AA chicken.

\subsection{Contents of Fatty Acids}

The fatty acid composition of meat was affected by many factors, such as age and genotype [21,29]. Furthermore, dietary manipulation can alter the fatty composition and fatty acid contents [45]. The different fatty acid compositions of muscles most likely affect lipid stability and flavor. Table 4 summarizes the fatty acid profiles in the breast muscle of these three breeds. The major components measured in the chicken meat from BJY, LH, and AA were linoleic acid (C 18:2), oleic acid (C 18:1), and palmitic acid (C 16:0), which accounted for approximately $70 \%$ of total fatty acids; this is consistent with the results reported by previous studies [5]. Regarding the total saturated acids (SFA), LH chickens showed significantly lower values $(32.21 \mathrm{mg} / 100 \mathrm{~g})$ in comparison to BJY and AA broilers, while there were no significant differences between BJY and AA broilers. However, the contents of unsaturated fatty acids (UFA) in AA broilers were significantly higher than those in BJY and LH chickens. Regarding UFA/SFA and PUFA/monounsaturated fatty acids (MUFA), the ratios were both significantly higher in BJY chickens than in LH chickens and AA broilers, which suggests that the composition of fatty acids in BJY chickens breast meat were better than that of same-age LH chickens and fast-growing AA broilers.

Table 4. Fatty acid contents of different types of chicken breast (mg/100 g).

\begin{tabular}{cccc}
\hline Fatty Acid (mg/100 g) & BJY & LH & AA \\
\hline Palmitic Acid C 16:0 & $19.02 \pm 1.12^{\mathrm{a}}$ & $21.88 \pm 2.41^{\mathrm{a}}$ & $65.75 \pm 2.83^{\mathrm{b}}$ \\
Stearic Acid C 18:0 & $16.37 \pm 1.87^{\mathrm{a}}$ & $10.34 \pm 2.25^{\mathrm{a}}$ & $27.00 \pm 2.12^{\mathrm{b}}$ \\
Oleic Acid C 18:1 & $26.90 \pm 3.37^{\mathrm{a}}$ & $15.9 \pm 1.12^{\mathrm{a}}$ & $91.25 \pm 5.30^{\mathrm{b}}$ \\
Linoleic Acid C 18:2 & $34.60 \pm 3.62^{\mathrm{b}}$ & $15.37 \pm 7.12^{\mathrm{a}}$ & $76.50 \pm 4.95^{\mathrm{c}}$ \\
Arachidonic Acid C 20:4 & $14.55 \pm 0.71^{\mathrm{a}}$ & $10.87 \pm 0.75^{\mathrm{b}}$ & $6.25 \pm 0.35^{\mathrm{c}}$ \\
Nervonic Acid C 24:1 & $5.43 \pm 1.31^{\mathrm{a}}$ & $6.89 \pm 1.12^{\mathrm{a}}$ & $3.63 \pm 1.94^{\mathrm{a}}$ \\
Total & $116.86 \pm 7.97^{\mathrm{b}}$ & $79.24 \pm 3.37^{\mathrm{a}}$ & $270.38 \pm 17.50^{\mathrm{c}}$ \\
SFA & $92.75 \pm 4.95^{\mathrm{a}}$ & $32.21 \pm 4.66^{\mathrm{b}}$ & $92.75 \pm 4.95^{\mathrm{a}}$ \\
MUFA & $32.33 \pm 2.06^{\mathrm{a}}$ & $22.79 \pm 2.25^{\mathrm{a}}$ & $94.88 \pm 7.25^{\mathrm{b}}$ \\
PUFA & $49.15 \pm 2.91^{\mathrm{b}}$ & $26.24 \pm 6.37^{\mathrm{a}}$ & $82.75 \pm 5.30^{\mathrm{c}}$ \\
UFA & $81.48 \pm 4.97^{\mathrm{b}}$ & $49.03 \pm 4.12^{\mathrm{a}}$ & $177.63 \pm 12.55^{\mathrm{c}}$ \\
PUFA/MUFA & $1.52 \pm 0.01^{\mathrm{a}}$ & $1.17 \pm 0.40^{\mathrm{a}}$ & $0.87 \pm 0.02^{\mathrm{a}}$ \\
UFA/SFA & $2.31 \pm 0.05^{\mathrm{b}}$ & $1.55 \pm 0.35^{\mathrm{a}}$ & $1.92 \pm 0.03^{\mathrm{c}}$ \\
\hline
\end{tabular}

$\overline{a, b, c}$ Means within a row with different superscripts differ significantly $(p<0.05)$. SFA = saturated fatty acids; MUFA = monounsaturated fatty acids; PUFA = polyunsaturated fatty acids; UFA = unsaturated fatty acids.

The arachidonic acid content (C 20:4) in BJY chickens was more than twice than that of AA broilers, which were $14.55 \mathrm{mg} / 100 \mathrm{~g}$ and $6.25 \mathrm{mg} / 100 \mathrm{~g}$, respectively. It was $10.87 \mathrm{mg} / 100 \mathrm{~g} \mathrm{C} \mathrm{20:4} \mathrm{in} \mathrm{LH} \mathrm{chickens,} \mathrm{which} \mathrm{was} \mathrm{higher} \mathrm{than} \mathrm{that} \mathrm{in} \mathrm{AA} \mathrm{broilers} \mathrm{but}$ 
lower than that in BJY chickens. Arachidonic acid can directly participate in intracellular signaling transduction and affect other signaling pathways to control cellular biological activity, which is a very important intracellular second messenger [46]. In addition, it was reported that, when the arachidonic acid composition was increased by supplementation with an acid enriched oil diet, the flavor intensity, total taste intensity, umami, and aftertaste of broiler muscle also increased [47]. Jeon et al. [48] found that the breast meat of Korean indigenous chickens had higher arachidonic acid contents than that of broilers. Zhao et al. [3] reported that the breast meat from BJY chickens contained significantly higher amounts of arachidonic acid than that of commercial fast-growing AA broilers at their market age. These results suggest that BJY chickens have better flavor properties and more nutritional value to humans than that of LH chickens and AA broilers.

\subsection{VOCs Analysis}

Table 5 shows the comparison of VOCs relevant contents of different types of chicken breast; 20, 25, and 19 VOCs were detected in the BJY, AA and LH, respectively. VOCs chromatograms of BJY, LH, and AA were showed in Figures S1-S3, respectively. There were no complicated heterocyclic compounds such as pyrroles and pyrazines in this study, which might be related to the lower maturation temperature $\left(60^{\circ} \mathrm{C}\right)$. Among the VOCs, 5 compounds were detected in all three types of chicken, including1, 3-bis (1,1-dimethylethyl)benzene, heneicosane, tetradecane, 2,4-bis (1,1-dimethylethyl)-enol, and hexadecanal. The volatile flavor substances together affect the final sensory quality of chicken meat. Jiang [49] found that the volatile compounds in Avain broilers, fast-da Yellow chicken, and BJY also contained tetradecane and palmaldehyde. It was predicted that tetradecane and hexadecanal were common volatile substances in chicken meat.

Table 5. Comparison of VOCs relevant contents of different types of chicken breast (\%).

\begin{tabular}{|c|c|c|c|}
\hline VOCs & BJY & LH & AA \\
\hline Hydrocarbons & & & \\
\hline (1-Hexadecylheptadecyl)-Cyclohexane & $2.13 \pm 0.01$ & - & - \\
\hline 1,3-Bis(1,1-dimethylethyl)-Benzene & $12.72 \pm 0.05$ & $17.68 \pm 0.00$ & $0.70 \pm 0.01$ \\
\hline 2-Methylhexacosane & - & - & $2.70 \pm 0.30$ \\
\hline (2,3-Dimethyldecyl)-Benzene & $2.27 \pm 0.01$ & - & - \\
\hline 2,4-dimethyl-1-Decene & - & $3.82 \pm 0.00$ & - \\
\hline 2,4-Dimethyl-Eicosane, & - & - & $0.39 \pm 0.01$ \\
\hline 2,6,10,14-Tetramethyl-Pentadecane & - & - & $11.19 \pm 0.03$ \\
\hline 2-Methyl-Dodecane & - & $2.45 \pm 0.01$ & - \\
\hline 2-Methyl-Hexadecane & - & - & $6.74 \pm 0.13$ \\
\hline 2-Methyltetracosane & $2.53 \pm 0.02$ & $2.72 \pm 0.16$ & - \\
\hline 3-Methyl-Heptadecane & - & - & $5.06 \pm 0.51$ \\
\hline 8-Heptyl-Pentadecane & - & - & $2.63 \pm 0.18$ \\
\hline 8-methyl-1-Undecene & - & $2.37 \pm 0.00$ & - \\
\hline 8-Methyl-Heptadecane & - & - & $1.60 \pm 0.04$ \\
\hline Decyl-Cyclohexane & - & - & $3.85 \pm 0.04$ \\
\hline Decyl-Cyclopentane & - & - & $1.18 \pm 0.01$ \\
\hline Undecyl-Cyclohexane & - & - & $2.19 \pm 0.03$ \\
\hline Dodecylcyclohexane & - & - & $2.03 \pm 0.11$ \\
\hline Eicosane & - & $0.74 \pm 0.00$ & $7.59 \pm 4.28$ \\
\hline Heneicosane & $13.36 \pm 0.66$ & $6.32 \pm 0.40$ & $19.05 \pm 0.59$ \\
\hline Heptadecane & - & - & $6.66 \pm 0.36$ \\
\hline Hentriacontane & - & $5.60 \pm 0.12$ & - \\
\hline Hexadecane & - & 1.0 & $4.90 \pm 0.99$ \\
\hline Octadecane & - & - & $3.73 \pm 0.08$ \\
\hline Squalane & - & - & $6.00 \pm 0.88$ \\
\hline Tetradecane & $1.28 \pm 0.01$ & $3.99 \pm 0.01$ & $0.82 \pm 0.01$ \\
\hline
\end{tabular}


Table 5. Cont.

\begin{tabular}{|c|c|c|c|}
\hline VOCs & BJY & LH & AA \\
\hline Alcohols & & & \\
\hline 1-Dodecanol & $2.74 \pm 0.00$ & $4.18 \pm 0.00$ & - \\
\hline 1-Octen-3-ol & $9.46 \pm 0.04$ & $14.62 \pm 0.35$ & - \\
\hline 2-(2-Ethoxyethoxy)-Ethanol & $13.76 \pm 2.33$ & $6.93 \pm 0.02$ & - \\
\hline 2-(Hexadecyloxy)-Ethanol & $2.74 \pm 0.00$ & - & - \\
\hline 2-methyl-1-Decanol & - & $2.30 \pm 0.07$ & - \\
\hline 2-Methyl-1-Hexadecanol & $2.67 \pm 0.12$ & - & - \\
\hline 5-Methyl-2-(1-methylethyl)-1-Hexanol & - & $4.28 \pm 0.07$ & - \\
\hline Octahydro-4a(2H)-Naphthalenemethanol & - & - & $0.41 \pm 0.01$ \\
\hline $\begin{array}{c}\text { 2,4-Bis(1,1-dimethylethyl)-enol } \\
\text { Aldehydes }\end{array}$ & $8.92 \pm 0.08$ & $13.36 \pm 0.03$ & $0.06 \pm 0.01$ \\
\hline Dodecanal & $2.28 \pm 0.01$ & $1.38 \pm 0.06$ & - \\
\hline Hexadecanal & $0.17 \pm 0.01$ & $2.31 \pm 0.05$ & $2.45 \pm 0.10$ \\
\hline Nonanal & - & $1.84 \pm 0.01$ & - \\
\hline Pentadecanal & $0.12 \pm 0.00$ & - & $2.92 \pm 0.01$ \\
\hline Tridecanal & $7.64 \pm 0.10$ & - & - \\
\hline $\begin{array}{c}\text { Tetradecanal } \\
\text { Esters }\end{array}$ & $2.04 \pm 0.01$ & - & - \\
\hline $\begin{array}{c}{\left[1,1^{\prime} \text {-Bicyclopropyl]-2-octanoic acid, 2'-hexyl-, }\right.} \\
\text { methyl ester }\end{array}$ & $2.21 \pm 0.01$ & - & - \\
\hline 2-Hexyldecyl propionate & - & - & $3.55 \pm 0.00$ \\
\hline 2-Thiopheneacetic acid, oct-3-en-2-yl ester & - & - & $1.59 \pm 0.00$ \\
\hline 9-Hexadecenoic acid, 9-hexadecenyl ester & $5.37 \pm 0.01$ & $3.11 \pm 0.01$ & - \\
\hline Docosanoic acid nonyl ester & $5.59 \pm 0.00$ & - & - \\
\hline
\end{tabular}

Table 6 shows the quantity and relative content of VOCs in different types of chicken meat. Hydrocarbons, alcohols, and aldehydes were major VOCs in all three chicken samples, and their contribution to chicken flavor varies with the substance threshold [50]. Hydrocarbons were mainly derived from the cleavage of fatty acid alkoxy radicals, and the differences in the contents might be caused by the differences in their precursor fatty acids. The relative contents and types of hydrocarbon compounds in the three muscles were quite different, which were consistent with the previous results of the fatty acid contents. The aroma threshold of hydrocarbons is relatively high, and it is generally believed that they have little direct contribution to the flavor of meat [51]. Alcohols are mainly derived from the oxidation and degradation of lipids, which have pleasant fruity and floral odors [52]. Among them, 1-octen-3-ol has a mushroom-like smell and is the product of arachidonic acid oxidation by lipoxygenase [24], which was detected in both BJY and LH. In this study, the quantity and relative contents of alcohols in BJY and LH chicken were higher than AA chicken. Aldehydes are aliphatic compounds produced by lipid oxidization and thermal degradation [53], which are usually considered to be the major flavor contributors to meat products due to their low thresholds [54]. Previous studies have proved that aldehydes such as nonanal and decanal were characteristic aroma substances of chicken [55]. Nonanal was mainly formed by the oxidation of linoleic acid [56]. The fat content of BJY was relatively higher, so the variety and relative content of the aldehydes detected were also higher than LH and AA, contributing to a richer flavor of the chicken. In addition, saturated linear aldehydes with high molecular weight may produce pungent odors. The content of Pentadecanal and Hexadecanal in AA was relatively high. Li et al. have found that Tetradecanal might be one of the sources of the unpleasant earthy smell in fish [24]. 
Table 6. Comparison of the VOCs of different types of chicken breast.

\begin{tabular}{|c|c|c|c|c|c|c|}
\hline \multirow{2}{*}{ VOCs } & \multicolumn{2}{|r|}{ BJY } & \multicolumn{2}{|r|}{ LH } & \multicolumn{2}{|r|}{ AA } \\
\hline & Quantity & Relative Content & Quantity & Relative Content & Quantity & Relative Content \\
\hline Hydrocarbons & 6 & $34.29 \%$ & 9 & $45.68 \%$ & 19 & $89.02 \%$ \\
\hline Alcohols & 6 & $31.36 \%$ & 5 & $32.32 \%$ & 1 & $0.41 \%$ \\
\hline Phenols & 1 & $8.92 \%$ & 1 & $13.36 \%$ & 1 & $0.06 \%$ \\
\hline Aldehydes & 5 & $12.25 \%$ & 3 & $5.53 \%$ & 2 & $5.37 \%$ \\
\hline
\end{tabular}

\subsection{Electronic Nose Analysis}

The increase in meat production and the need for rapid detection have contributed to the development of simple, fast, accurate, and inexpensive methods to evaluate the classification or quality of meat [48]. Figure 3 shows how the electronic nose simulates the olfaction.

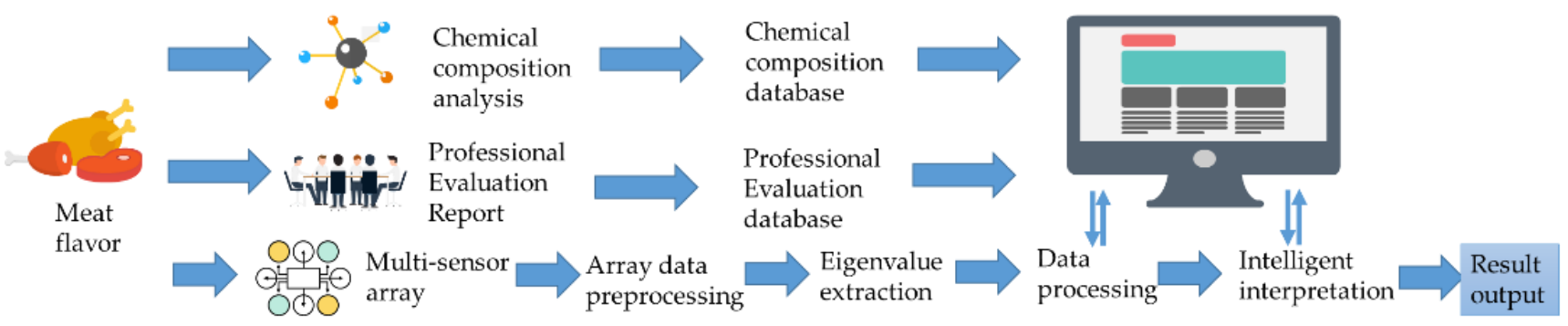

Figure 3. Simulation of the olfaction by electronic nose technology.

The multivariate recognition algorithm to process the multi-sensor array signals is based on the linear discriminant analysis method [57]. Because the process is simple and economical, sample preparation is minimal, and reading and interpretation of the measurements are clear, the electronic nose has become a viable alternative to conventional analysis [11,58] and has been applied to evaluate the shelf-life of livestock products [59], and to analyze meat quality [60].

In the present study, there were nine eigenvalues of 16 sensors of the electronic nose, including means, integral value, differential value, range, quadratic coefficient, primary coefficient, halfwidth, primary coefficient of logarithmic regression function, and constant term of logarithmic regression function, which were used to analyze these three breeds of chicken [61]. They could be accurately identified with the CDA to analyze the acquired data in order to evaluate the overall flavor characteristics among the three chicken breeds. As shown in Figure 4, the CDA based on the 144 parameters derived the first and second canonical variables (CN1 and $\mathrm{CN} 2$, respectively). CAN1 explained $93.4 \%$ of the variability and was able to differentiate BJY and LH chickens from AA broilers. Furthermore, CAN2 was able to separate BJY from LH chickens. The results indicate that the distance between the core of BJY chickens and LH chickens was relatively close, but it could also be completely separated. The possible reason is that these two breeds of chicken were fed in the same environment and at the same age.

The above studies have shown that electronic nose technology can be used to successfully distinguish the volatile compounds among these three breeds of chickens. This method exhibits satisfactory results using appropriate pattern recognition techniques for data analysis, which provides a gratifying analytical method for Beijing-you chicken identification. With the advantages of high sensitivity and excellent selectivity, the electronic nose has broad application prospects for the detection of meat adulteration in the future. 


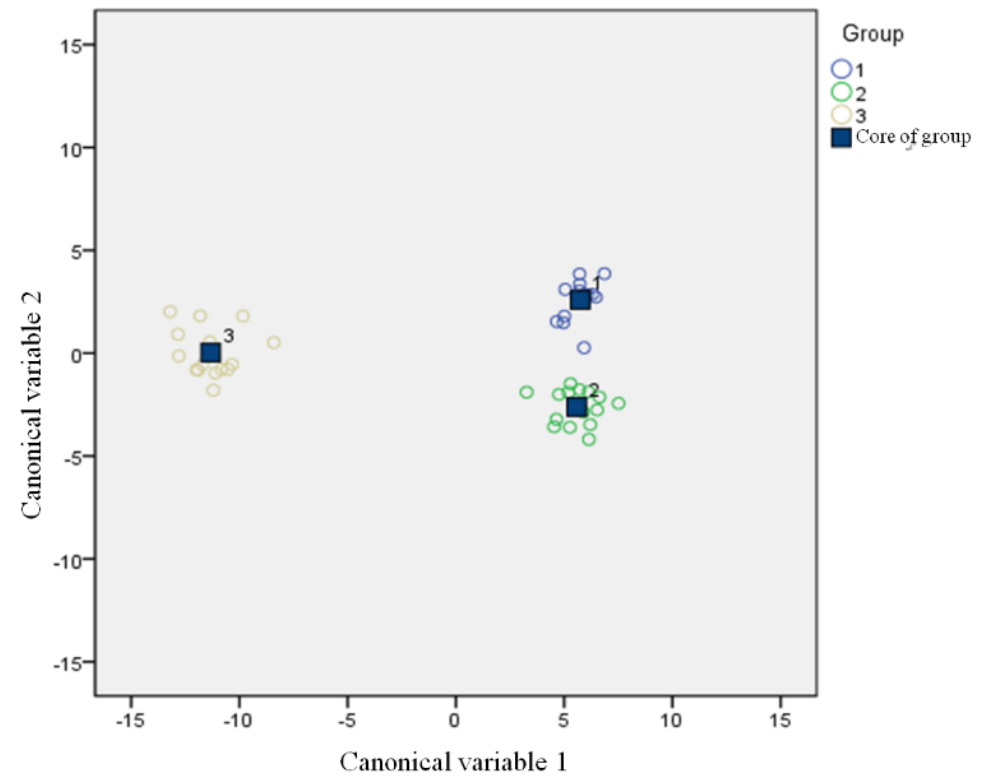

Figure 4. Canonical discriminant analysis of the three types of chicken breast: Group 1, 2, and 3 represent BJY, LH, and AA, respectively.

\section{Conclusions}

This study demonstrated several differences among BJY chickens, LH chickens, and AA broilers in terms of nutritional and sensory properties. At their typical market ages, 240-day-old BJY was preferable to 240-day-old LH and 42-day-old AA broilers due to its higher protein content, higher IMP and GMP content, and lower Hx and HxR content. Noticeably, BJY chicken showed an especially high arachidonic acid (14.55 mg/100 g) and essential amino acids content $(127.84 \mathrm{mg} / 100 \mathrm{~g})$. These characteristics might contribute to better flavor properties and higher nutritional value to humans, which would meet the preference of those consumers in the current market. The relative contents and varieties of VOCs, detected by SPME-GC/MS, were quite different between the three chicken breeds, which resulted in differences in the flavors. The variety and relative content of aldehydes might contribute to a richer flavor of the chicken. Furthermore, the electronic nose results also confirmed that there were significant differences between the breast meat of these three breeds of chicken by canonical discriminant analysis. The results revealed the meat characteristics of BJY chicken and perhaps provide a possible adulteration identification method, which can help consumers choose premium chicken meat in the market.

Supplementary Materials: The following are available online at https:/ / www.mdpi.com/article / 10.3390/foods11060782/s1, Figure S1: VOCs chromatograms of BJY breast, Figure S2: VOCs chromatograms of LH breast, Figure S3: VOCs chromatograms of AA breast.

Author Contributions: Conceptualization, X.L. (Xingmin Li), W.Y. and R.D.; methodology, Y.F. and F.J.; resources, X.L. (Xueze Lv) and L.W.; writing-original draft preparation, J.C. All authors have read and agreed to the published version of the manuscript.

Funding: This research was funded by the Beijing Poultry Industry Innovation Team Project (BAIC04-2021).

Institutional Review Board Statement: Not applicable.

Informed Consent Statement: Not applicable.

Data Availability Statement: Data is contained within the article.

Acknowledgments: This study was supported by the earmarked fund for the Beijing Poultry Industry Innovation Team Project (BAIC04-2021).

Conflicts of Interest: The authors declare no conflict of interest. 


\section{References}

1. Fu, D.; Zhang, D.; Xu, G.; Li, K.; Wang, Q.; Zhang, Z.; Li, J.; Chen, Y.; Jia, Y.; Qu, L.J. Effects of different rearing systems on meat production traits and meat fiber microstructure of Beijing-you chicken. Anim. Sci. J. 2015, 86, 729-735. [CrossRef]

2. Zheng, P. Breeds of Domesticated Animal and Poultry in China; Shanghai Scientific and Technical Publishers: Shanghai, China, 1988.

3. Zhao, G.P.; Cui, H.X.; Liu, R.R.; Zheng, M.Q.; Chen, J.L.; Wen, J. Comparison of breast muscle meat quality in 2 broiler breeds. Poult. Sci. 2011, 90, 2355-2359. [CrossRef] [PubMed]

4. Zdanowska-Sąsiadek, Ż.; Marchewka, J.; Horbańczuk, J.O.; Wierzbicka, A.; Lipińska, P.; Jóźwik, A.; Atanasov, A.G.; Huminiecki, Ł.; Sieroń, A.; Sieroń, K.; et al. Nutrients composition in fit snacks made from ostrich, beef and chicken dried meat. Molecules 2018, 23, 1267. [CrossRef] [PubMed]

5. Yulian, C.; Yan, Q.; Yu, X.; Haochun, C.; Liang, Z.; Ming, H.; Guanghong, Z. Differences in Physicochemical and Nutritional Properties of Breast and Thigh Meat from Crossbred Chickens, Commercial Broilers, and Spent Hens. Asian Australas. J. Anim. Sci. 2016, 29, 855-864.

6. Abrodo, P.A.; Llorente, D.D.; Corujedo, S.J.; de la Fuente, E.D.; Álvarez, M.D.G.; Gomis, D.B. Characterisation of Asturian cider apples on the basis of their aromatic profile by high-speed gas chromatography and solid-phase microextraction. Food Chem. 2010, 121, 1312-1318. [CrossRef]

7. Zhu, D.; Ren, X.; Wei, L.; Cao, X.; Li, J. Collaborative analysis on difference of apple fruits flavour using electronic nose and electronic tongue. Sci. Hortic. 2020, 260, 108879. [CrossRef]

8. Shi, L.K.; Zhang, D.D.; Liu, Y.L. Survey of polycyclic aromatic hydrocarbons of vegetable oils and oilseeds by GC-MS in China. Food Addit. Contam. A 2016, 33, 603-611. [CrossRef]

9. Bartlett, G. A brief history of electronic noses. Sens. Actuators B Chem. 1994, 18, 211-220.

10. Górska-Horczyczak, E.; Guzek, D.; Molęda, Z.; Wojtasik-Kalinowska, I.; Brodowska, M.; Wierzbicka, A. Applications of electronic noses in meat analysis. Food Sci. Technol. 2016, 7, 389-395. [CrossRef]

11. Chen, J.; Gu, J.; Zhang, R.; Mao, Y.; Tian, S. Freshness evaluation of three kinds of meats based on the Electronic Nose. Sensors 2019, 19, 605. [CrossRef]

12. Wijaya, D.R.; Sarno, R.; Zulaika, E.; Sabila, S.I. Development of mobile electronic nose for beef quality monitoring. Procedia Comput. Sci. 2017, 124, 728-735. [CrossRef]

13. Gliszczyńska-Świgło, A.; Chmielewski, J. Electronic Nose as a tool for monitoring the authenticity of food. A Review. Food Anal. Methods 2016, 10, 1800-1816. [CrossRef]

14. Tian, X.; Wang, J.; Cui, S. Analysis of pork adulteration in minced mutton using electronic nose of metal oxide sensors. J. Food Eng. 2013, 119, 744-749. [CrossRef]

15. Song, S.; Tang, Q.; Hayat, K.; Karangwa, E.; Zhang, X.; Xiao, Z. Effect of enzymatic hydrolysis with subsequent mild thermal oxidation of tallow on precursor formation and sensory profiles of beef flavours assessed by partial least squares regression. Meat Sci. 2014, 96, 1191-1200. [CrossRef]

16. Wojtasik-Kalinowska, I.; Guzek, D.; Górska-Horczyczak, E.; Głąbska, D.; Brodowska, M.; Sun, D.; Wierzbicka, A. Volatile compounds and fatty acids profile in Longissimus dorsi muscle from pigs fed with feed containing bioactive components. LWT Food Sci. Technol. 2016, 67, 112-117. [CrossRef]

17. Rajkumar, U.; Muthukumar, M.; Haunshi, S.; Niranjan, M.; Raju MV, L.N.; Rama Rao, S.V.; Chatterjee, R.N. Comparative evaluation of carcass traits and meat quality in native Aseel chickens and commercial broilers. Br. Poult. Sci. 2016, 57, 56-65. [CrossRef]

18. Phatthawin, L.; Rawiwan, W.; Thanaporn, B.; Arpamas, C.; Niraporn, C.; Sanchai, J. Taste-Active and Nutritional Components of Thai Native Chicken Meat: A Perspective of Consumer Satisfaction. Food Sci. Anim. Resour. 2021, 41, $237-246$.

19. Farkaš, P.; Sádecká, J.; Kováč, M.; Siegmund, B.; Leitner, E.; Pfannhauser, W. Key odourants of pressure-cooked hen meat. Food Chem. 1997, 60, 617-621. [CrossRef]

20. Xiaojun, J.; Jingting, S.; Ming, Z.; Yifan, L.; Yunjie, T.; Gaige, J.; Yanju, S.; Jianmin, Z. Comparative analysis of quality and flavor of broiler chickens in different breeds and feeding cycles. Chin. J. Anim. Nutr. 2018, 30, 2421-2430.

21. Jung, S.; Lee, K.H.; Nam, K.C.; Jeon, H.J.; Jo, C. Quality Assessment of the Breast Meat from WoorimatdagTM and Broilers. Korean J. Food Sci. Anim. Resour. 2014, 34, 709-716. [CrossRef]

22. Li, X.; Rezaei, R.; Peng, L.; Wu, G. Composition of amino acids in feed ingredients for animal diets. Amino Acids 2011, 40, 1159-1168. [CrossRef] [PubMed]

23. Gecgel, U. Changes in some physicochemical properties and fatty acid composition of irradiated meatballs during storage. J Food Sci. Technol. 2013, 50, 505-513. [CrossRef] [PubMed]

24. Li, Q.; Zhang, L.T.; Luo, Y.K. Changes in microbial communities and quality attributes of white muscle and dark muscle from common carp (Cyprinus carpio) during chilled and freeze-chilled storage. Food Microbiol. 2018, 73, 237-244. [CrossRef] [PubMed]

25. Fernandez, X.; Monin, G.; Talmant, A.; Mourot, J. Influence of intramuscular fat content on the quality of pig meat-1. Composition of the lipid fraction and sensory characteristics of m. longissimus lumborum. Meat Sci. 1999, 53, 59-65. [CrossRef]

26. Talpur, M.Z.; Wang, K.; Ahmed, I.; Li, Z.; Liu, L.; Li, Q.; Dou, T.; Gu, D.; Xu, Z.; Rong, H.; et al. Analysis of differentially expressed genes related to intramuscular fat and chemical composition in different breeds of chicken. Pak. J. Agric. Sci. 2018, 55, 615-623.

27. Intarapichet, K.O.; Suksombat, W.; Maikhunthod, B. Chemical Compositions, Fatty Acid, Collagen and Cholesterol Contents of Thai Hybrid Native and Broiler Chicken Meats. J. Poult. Sci. 2008, 45, 7-14. [CrossRef] 
28. Dikeman, M.E.; Pollak, E.J.; Zhang, Z.; Moser, D.W.; Gill, C.A.; Dressler, E.A. Phenotypic ranges and relationships among carcass and meat palatability traits for fourteen cattle breeds, and heritabilities and expected progeny differences for Warner-Bratzler shear force in three beef cattle breeds. J. Anim. Sci. 2005, 83, 2461-2467. [CrossRef]

29. Ranran, L.; Hongyang, W.; Jie, L.; Jie, W.; Maiqing, Z.; Xiaodong, T.; Siyuan, X.; Huanxian, C.; Qinghe, L.; Guiping, Z. Uncovering the embryonic development-related proteome and metabolome signatures in breast muscle and intramuscular fat of fast-and slow-growing chickens. BMC Genom. 2017, 18, 816.

30. Tang, H.; Gong, Y.Z.; Wu, C.X.; Jiang, J.; Wang, Y.; Li, K. Variation of meat quality traits among five genotypes of chicken. Poult. Sci. 2009, 88, 2212-2218. [CrossRef]

31. Samooel, J.; Sik, B.Y.; Joo, K.H.; Jayasena, D.D.; Heon, L.J.; Bok, P.H.; Nyung, H.K.; Cheorun, J. Carnosine, anserine, creatine, and inosine $5^{\prime}$-monophosphate contents in breast and thigh meats from 5 lines of Korean native chicken. Poult. Sci. 2013, 92, 3275-3282.

32. Misako, K.; Atsushi, O.; Yoichi, U. Taste enhancements between various amino acids and IMP. Chem. Senses 2002, $27,739-745$.

33. Fukuuchi, T.; Iyama, N.; Yamaoka, N.; Kaneko, K. Simultaneous quantification by HPLC of purines in umami soup stock and evaluation of their effects on extracellular and intracellular purine metabolism. Nucleos. Nucleot. Nucl. 2018, 37, 273-279. [CrossRef] [PubMed]

34. Wang, Z.; Zhang, Q.; Hu, X. Effects of fermentive Chinese herbal medicine, antibiotics and age on slaughter performance and meat quality of broilers. China Poult. 2016, 38, 33-36.

35. Shi, J.; Wang, S.; Gong, J.; Gu, S.Q.; Zhuang, J.; Wang, X. Effect of different fatting models on non-volatile taste active compounds of Chinese mitten crab (Eriocheir sinensis) meat. Sci. Technol. Food Ind. 2015, 36, 347-351.

36. Pan, J.; Yang, J.-J.; Zhu, S.-J.; Wu, Z.-Y. Comparison of taste compounds in pork from four different breeds. Sci. Technol. Food Ind. 2015, 36, 161-164.

37. Dashmaa, D.; Yang, J.; Ba, H.V.; Ryu, K.S.; Hwang, I. Differences in the taste-active compounds between hanwoo longissimus and semitendinosus muscles and its comparision with angus longissimus beef muscle. Korean J. Food Sci. Anim. Resour. 2013, 33, 508-514. [CrossRef]

38. Bo, H.; Yoon, S.S.; Han, H.R.; Wang, X. Effects of l-arginine on endothelium derived factors and cyclic nucleotides in broilers under low ambient temperature. Asian Australas. J. Anim. Sci. 2004, 17, 1570-1574.

39. Howgate, P. A review of the kinetics of degradation of inosine monophosphate in some species of fish during chilled storage. Int. J. Food Sci. Technol. 2006, 41, 341-353. [CrossRef]

40. Wen, D.; Liu, Y.; Yu, Q. Metabolomic approach to measuring quality of chilled chicken meat during storage. Poult. Sci. 2020, 99, 2543-2554. [CrossRef]

41. Barton, L.; Bures, D.; Kotrba, R.; Sales, J. Comparison of meat quality between eland (Taurotragus oryx) and cattle (Bos taurus) raised under similar conditions. Meat Sci. 2014, 96, 346-352. [CrossRef]

42. Geldenhuys, G.; Hoffman, L.C.; Muller, N. The fatty acid, amino acid, and mineral composition of Egyptian goose meat as affected by season, gender, and portion. Poult. Sci. 2015, 94, 1075-1087. [CrossRef] [PubMed]

43. Xianyong, M.; Miao, Y.; Zhichang, L.; Dun, D.; Yiyan, C.; Zhimei, T.; Gang, W. Effect of amino acids and their derivatives on meat quality of finishing pigs. J. Food Sci. Technol. 2020, 57, 404-412.

44. Wattanachant, S.; Benjakul, S.; Ledward, D.A. Composition, color, and texture of Thai indigenous and broiler chicken muscles Poult. Sci. 2004, 83, 123-128. [CrossRef] [PubMed]

45. Kamboh, A.A.; Zhu, W.Y. Effect of increasing levels of bioflavonoids in broiler feed on plasma anti-oxidative potential, lipid metabolites, and fatty acid composition of meat. Poult. Sci. 2013, 92, 454-461. [CrossRef]

46. Kucheruk, M.; Midyk, S.; Zasekin, D.; Ushkalov, V.; Kepple, O. Comparison of fatty acid content of organic and traditionally grown broiler chickens. Food Sci. Technol. 2019, 13, 51-57. [CrossRef]

47. Jayasena, D.D.; Jung, S.; Kim, H.J.; Bae, Y.S.; Yong, H.I.; Lee, J.H.; Kim, J.G.; Jo, C. Comparison of Quality Traits of Meat from Korean Native Chickens and Broilers Used in Two Different Traditional Korean Cuisines. Asian Australas. J. Anim. 2013, 26, 1038-1046. [CrossRef]

48. Jeon, H.J.H.; Choe, J.C.J.; Jung, Y.J.Y.; Kruk, Z.K.Z.A.; Lim, D.L.D.; Jo, C.J.C. Comparison of the Chemical Composition, Textural Characteristics, and Sensory Properties of North and South Korean Native Chickens and Commercial Broilers. Food Sci. Anim. Resour. 2010, 30, 171-178. [CrossRef]

49. Jiang, L. Comparation of the Chemical Composition in Different Kinds of Broilers Meat and the Relationship with the Flavor; Huazhong Agricultural University: Wuhan, China, 2006.

50. Lorenzo, J.M.; Franco, D. Fat effect on physico-chemical, microbial and textural changes through the manufactured of dry-cured foal sausage Lipolysis, proteolysis and sensory properties. Meat Sci. 2012, 92, 704-714. [CrossRef]

51. Garcia, C.; Berdagué, J.J.; Antequera, T.; López-Bote, C.; Córdoba, J.J.; Ventanas, J. Volatile components of dry cured Iberian ham. Food Chem. 1991, 41, 23-32. [CrossRef]

52. Gaspardo, B.; Procida, G.; Toso, B.; Stefanon, B. Determination of volatile compounds in San Daniele ham using headspace GC-MS. Meat Sci. 2008, 80, 204-209. [CrossRef]

53. Zhao, J.; Wang, M.; Xie, J.; Zhao, M.; Hou, L.; Liang, J.; Wang, S.; Cheng, J. Volatile flavor constituents in the pork broth of black-pig. Food Chem. 2017, 226, 51-60. [CrossRef] [PubMed]

54. Maarse, H.; Visscher, C. Volatile compounds in food-Qualitative and quantitative data. Food Chem. 1991, 39, 120-122. 
55. Farmer, L. Poultry meat flavor. Poult. Meat Sci. 1999, 12, 127-158.

56. Iglesias, J.; Medina, I.; Bianchi, F.; Careri, M.; Mangia, A.; Musci, M. Study of the volatile compounds useful for the characterisation of fresh and frozen-thawed cultured gilthead sea bream fish by solid-phase microextraction gas chromatography-mass spectrometry. Food Chem. 2009, 115, 1473-1478. [CrossRef]

57. Kiselev, I.; Sysoev, V.; Kaikov, I.; Koronczi, I.; Adil Akai Tegin, R.; Smanalieva, J.; Sommer, M.; Ilicali, C.; Hauptmannl, M. On the Temporal Stability of analyte recognition with an E-nose based on a metal Oxide senso array in practical application. Sensors 2018, 18, 550. [CrossRef]

58. Peris, M.; Escuder-Gilabert, L. On-line monitoring of food fermentation processes using electronic noses and electronic tongues: A review. Anal. Chim. Acta 2013, 804, 29-36. [CrossRef]

59. Narsaiah, K.; Jha, S.N. Nondestructive methods for quality evaluation of livestock products. J. Food Sci. Technol. 2012, 49, 342-348. [CrossRef]

60. Jin, Y.; Cui, H.; Yuan, X.; Liu, L.; Liu, X.; Wang, Y.; Ding, J.; Xiang, H.; Zhang, X.; Liu, J.; et al. Identification of the main aroma compounds in Chinese local chicken high-quality meat. Food Chem. 2021, 39, 129930. [CrossRef]

61. Jiang, Q.; Zheng, L.; Tian, L.; Cheng, G.; Meng, W. Application of Electronic Nose in Aroma Prediction of Pork Balls. Food Sci. 2018, 39, 228-233. 